\title{
Acute Myeloid Leukemia with Multilineage Dysplasia in Remission
}

National Cancer Institute

\section{Source}

National Cancer Institute. Acute Myeloid Leukemia with Multilineage Dysplasia in

Remission. NCl Thesaurus. Code C156724.

Acute myeloid leukemia with multilineage dysplasia which is not growing and responds to treatment. 